\title{
Time sequence of changes in the responsiveness of glycogen breakdown to adrenergic agonists in perfused liver of rats with insulin-induced hypoglycemia
}

\author{
M. Vardanega-Peicher ${ }^{1}$, \\ G. Lopes' ${ }^{1}$, F.B. Lima², \\ R. Curi2 ${ }^{2}$ L.C. Nakano 3 \\ and R.B. Bazotte ${ }^{1}$
}

\author{
1Departamento de Farmácia e Farmacologia, U niversidade Estadual de Maringá, \\ Maringá, PR, Brasil \\ 2Departamento de Fisiologia e Biofísica, Instituto de Ciências Biomédicas, \\ Universidade de São Paulo, São Paulo, SP, Brasil \\ ${ }^{3}$ Departamento de Farmácia, Universidade Paranaense, U muarama, PR, Brasil
}

\section{Correspondence \\ R.B. Bazotte \\ Departamento de Farmácia e \\ Farmacologia \\ Universidade Estadual de Maringá \\ 87020-900 Maringá, PR \\ Brasil \\ Fax: + 55-044-263-6231 \\ E-mail: rbbazotte@uem.br}

Research supported by PRONEX (No. 168/97). Publication supported by FAPESP.

\section{Abstract}

The time-course changes of the responsiveness of glycogen breakdown to $\alpha$-and $\beta$-adrenergic agonists during insulin-induced hypoglycemia (IIH) were investigated. Blood glucose levels were decreased prior to the alteration in the hepatic responsiveness to adrenergic agonists. The activation of hepatic glucose production and glycogenolysis by phenylephrine $(2 \mu \mathrm{M})$ and isoproterenol $(20 \mu \mathrm{M})$ was decreased in IIH. The changes in the responsiveness of glycogen catabolism were first observed for isoproterenol and later for phenylephrine. Hepatic $\beta$-adrenergic receptors showed a higher degree of adrenergic desensitization than did $\alpha$-receptors. Liver glycogen synthase activity, glycogen content and the catabolic effect of dibutyryl cyclic AMP (the $ß$-receptor second messenger) were not affected by IIH.

\section{Introduction}

The effect of epinephrine is known to be mediated by either $\alpha$ - or $\beta$-adrenergic receptors. The response of liver glycogen breakdown to epinephrine has been reported to vary with animal species (1), being influenced by a period of fasting (2), training for a starvation schedule (3), steroid hormones (4), sex (5), adrenalectomy (6), hypothyroidism (7), and aging (8). It should be mentioned that the effects on adrenergic receptors observed in vivo could not be fully re-
Key words

- Hypoglycemia

- Adrenergic responsiveness

- Insulin-induced hypoglycemia

- Hepatic glucose production

- Glycogenolysis produced in hepatocyte culture (9).

Recently, we developed a rat model to investigate hypoglycemia induced by insulin $(10,11)$. Using this model, we have shown decreased hepatic responsiveness to phenylephrine (an $\alpha$-adrenergic agonist) and isoproterenol (a $\beta$-adrenergic agonist), but not to glucagon or cyanide (12). However, all of these experiments were performed at a fixed time, i.e., 60 min after insulin injection.

For this reason, we determined the time sequence of changes in the responsiveness of 
glycogen breakdown to $\alpha$ - and $\beta$-adrenergic agonists in perfused liver of rats with insulin-induced hypoglycemia (IIH). The hepatic responsiveness to phenylephrine and isoproterenol was examined 15, 30, 60 and 120 min after insulin administration. For this purpose, isolated liver perfused with nonrecirculating medium was employed. This technique is suitable since metabolites do not accumulate, and metabolite rates can be determined directly from the metabolic concentrations in the perfusate effluent. Therefore, the release of pyruvate, L-lactate and glucose reflects almost quantitatively the glycogen breakdown. Moreover, additional experiments were performed to elucidate the mechanism by which IIH decreases hepatic responsiveness of liver glycogen breakdown to adrenergic agonists using dibutyryl cyclic AMP.

\section{Material and Methods}

Albino male Wistar fed rats weighing about $200 \mathrm{~g}$ were used. Hypoglycemia was induced by an intraperitoneal injection of 1 $\mathrm{U} / \mathrm{kg}$ of regular insulin (IN group). Control rats were injected with the same volume of saline (CN group). Liver perfusion was performed 15, 30, 60 and 120 min after insulin or saline administration. The rats were anesthetized by intraperitoneal injection of pentobarbital sodium $(40 \mathrm{mg} / \mathrm{kg})$. After laparotomy, blood was collected from the vena cava for determination of glucose (13) and insulin (14). Livers were perfused in situ using an open system with no recirculation of the perfusion fluid as previously described (15). After $10 \mathrm{~min}$ of perfusion (10-min time) phenylephrine $(2 \mu \mathrm{M})$, isoproterenol $(20 \mu \mathrm{M})$ or dibutyryl cyclic AMP $(30 \mu \mathrm{M})$ was dissolved in the perfusion fluid and infused between the 10th and 30th min of the perfusion period.

Glucose (13), L-lactate (16) and pyruvate (17) were measured at 2-min intervals in the perfusate effluent. Assuming that L- lactate, pyruvate and glucose released into the perfusate are the main products of carbohydrate degradation, glycogenolysis can be calculated as the sum of glucose plus the half-sum of L-lactate and pyruvate [glucose $+1 / 2$ (L-lactate + pyruvate)]. The release of these metabolites provides a good approximation of the rate of glycogenolysis because pyruvate oxidation, pentose-monophosphate shunt and recycling of pyruvate to glucose are minimal (18).

All metabolic measurements are reported as $\mu \mathrm{mol} \mathrm{\text {min } ^ { - 1 } \mathrm { g } \text { tissue }}{ }^{-1}$ fresh weight. In part of the experiments, liver samples were collected $10 \mathrm{~min}$ before infusion (time $0 \mathrm{~min}$ ) of phenylephrine or isoproterenol to measure hepatic glycogen concentration (19) and glycogen synthase activity (20). A similar procedure has been used in our previous studies (10-12).

Data were analyzed statistically by the unpaired Student $t$-test or ANOVA using the Primer Biostatistics software. A 95\% confidence level was accepted for all comparisons. The GraphPad Prism computer program was used to calculate the areas under the curves (AUCs) reported as $\mu \mathrm{mol} / \mathrm{g}$. Data are reported as means \pm SEM.

\section{Results}

Insulin administration caused a sustained decrease of glycemia from the 15 th to the 120 th $\min$ (Table 1). Since at this time glycemia had returned to normal in half the animals, we divided them into recovered and not recovered groups, respectively representing rats with normoglycemia and hypoglycemia 120 min after insulin administration. In contrast, insulin injection caused a slight not significant decrease of hepatic glycogen content (Table 2).

Since hypoglycemia was established, as early as after $30 \mathrm{~min}$ of insulin administration, this period of time was then chosen to carry out the liver perfusion experiments. As shown in Figure 1, the infusion of phenyl- 
ephrine or isoproterenol promoted a rapid and transient increase of hepatic glucose production and glycogenolysis in normoglycemic (CN group) and hypoglycemic rats (IN group). Peak values were obtained $2 \mathrm{~min}$ after the beginning of the infusion of both adrenergic agonists. The values of AUC calculated by subtracting the basal rates indicate that the activation of hepatic glucose production (Figure 1A) and glycogenolysis (Figure 1B) by isoproterenol was clearly decreased by hypoglycemia (IN group). On the other hand, the increment of hepatic glucose production (Figure 1C) and glycogenolysis (Figure 1D) promoted by phenylephrine did not differ between the $\mathrm{CN}$ and IN groups.

Since decreased responsiveness to isoproterenol was observed as early as after 30 min of insulin administration, we decided to verify if this change could be observed earlier, i.e., $15 \mathrm{~min}$ after insulin administration. Our results demonstrated that the increment of hepatic glucose production and glycogenolysis promoted by isoproterenol did not differ between the $\mathrm{CN}$ and IN groups (data not shown).

The maximal difference between the $\mathrm{CN}$ and IN groups was found at $60 \mathrm{~min}$ after insulin administration (Figure 2). At this time, the stimulation of hepatic glucose production (Figure 2A,C) and glycogenolysis (Figure 2B,D) by $\alpha$ - and $\beta$-adrenergic agonists was clearly lower $(\mathrm{P}<0.05)$.

The responsiveness of liver glycogen breakdown was investigated 120 min after insulin administration. The recovered group showed similar hepatic glucose production (Figure 3A,C) and rates of glycogenolysis (Figure 3B,D) during the infusion of either isoproterenol or phenylephrine. In contrast, the non-recovered group displayed lower adrenergic responsiveness as reflected by the decreased glucose production (Figure $4 \mathrm{~A}, \mathrm{C}$ ) and rate of glycogenolysis (Figure $4 \mathrm{~B}, \mathrm{D})$ during the infusion of isoproterenol

\begin{tabular}{|c|c|c|c|c|c|}
\hline \multirow[t]{2}{*}{ Groups } & \multicolumn{5}{|c|}{ Periods of time (min) } \\
\hline & 15 & 30 & 60 & 120 recovered & 120 not recovered \\
\hline $\mathrm{CN}$ & $146 \pm 5.21$ & $135 \pm 2.23$ & $135 \pm 3.61$ & $142 \pm 4.80$ & $141 \pm 3.92$ \\
\hline IN & $114 \pm 11.87$ & $58 \pm 8.84 *$ & $40 \pm 4.2^{*}$ & $132 \pm 6.19$ & $38 \pm 2.27 *$ \\
\hline
\end{tabular}

Table 2 - Liver glycogen content (mg\%) determined 15, 30, 60, and 120 min after injection of insulin (IN group) or saline (CN group).

Data are reported as the mean \pm SEM for at least 5 experiments.

\begin{tabular}{lccccc}
\hline Groups & \multicolumn{5}{c}{ Periods of time $(\mathrm{min})$} \\
\cline { 2 - 6 } & 15 & 30 & 60 & 120 recovered & 120 not recovered \\
\hline CN & $2.30 \pm 0.18$ & $2.62 \pm 0.28$ & $1.52 \pm 0.58$ & $2.26 \pm 0.25$ & $1.80 \pm 0.11$ \\
IN & $1.92 \pm 0.21$ & $2.19 \pm 0.20$ & $1.37 \pm 0.55$ & $2.18 \pm 0.17$ & $1.38 \pm 0.16$
\end{tabular}


Figure 1 - Effect of isoproterenol (20 $\mathrm{MM}$; panels $\mathrm{A}$ and $\mathrm{B})$ and phenylephrine $(2 \mu \mathrm{M}$; panels $\mathrm{C}$ and $D$ ) on glucose production and glycogenolysis. The data reported are the mean of 5-8 individual liver perfusion experiments performed $30 \mathrm{~min}$ after injection of saline (CN group, squares) or insulin (IN group, diamonds). The livers were perfused as described in Material and Methods. AUC = Area under the curve. The statistical test used was the unpaired Student t-test. and phenylephrine.

To better understand why hepatic glycogen content was not affected by hypoglycemia (Table 2), we measured glycogen synthase activity. As shown in Table 3 , total synthase activity and the proportion of the active form were not influenced by IIH.

Finally, in the last set of experiments the effect of dibutyryl cyclic AMP on hepatic glucose production and glycogenolysis was investigated. The kinetics of the activation of glycogen catabolism was similar in the two groups (Figure 5). However, the responses of the liver from hypoglycemic rats were slightly less pronounced, as indicated by their glycogen content (Table 2).
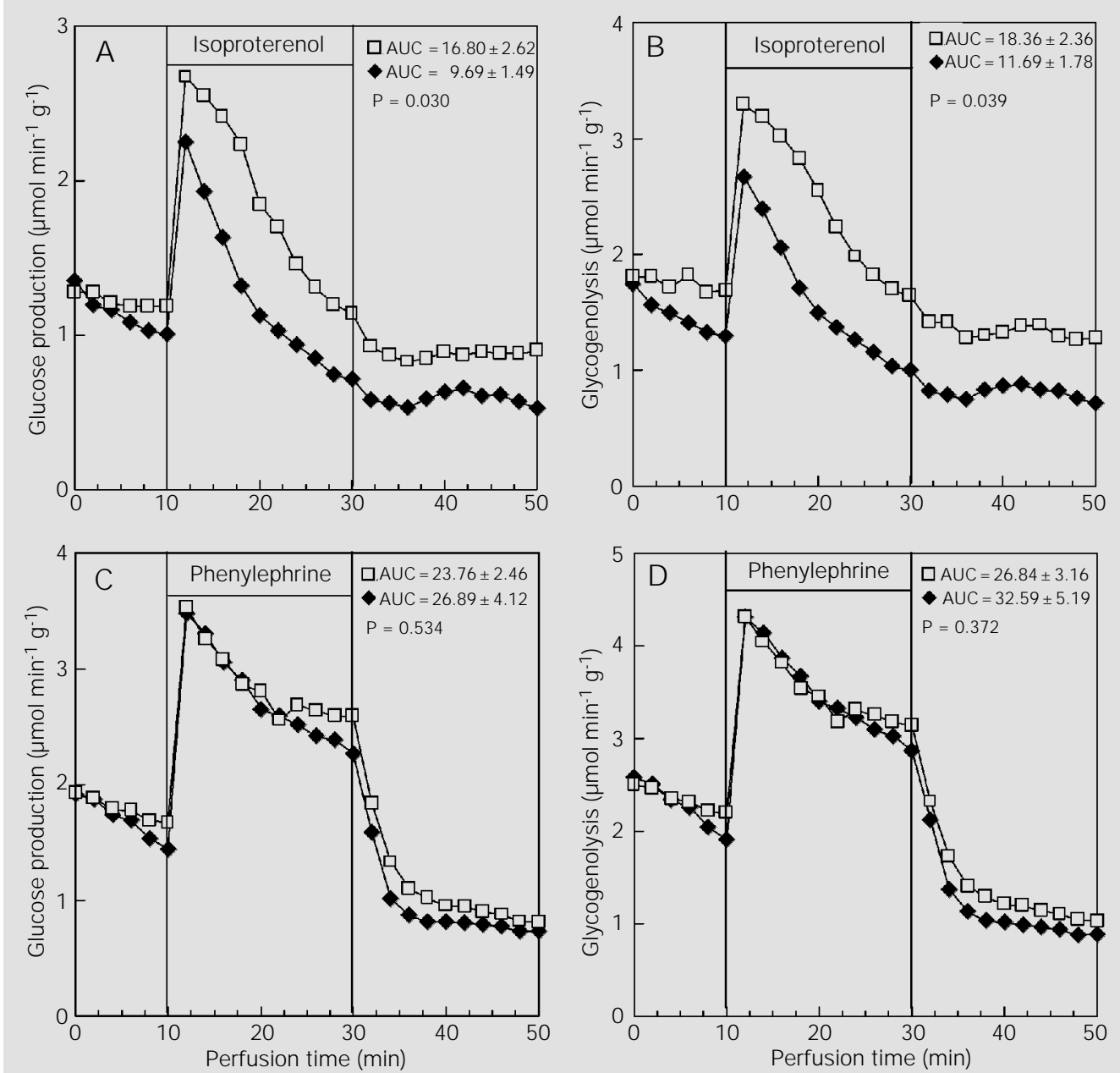
during hypoglycemia to $\alpha$ - and $\beta$-adrenergic agonists was investigated.

Glycemia decreased before the alteration of hepatic responsiveness. However, the responsiveness of glycogenolysis to phenylephrine and isoproterenol varied extensively along the experiment. Decreased responsiveness to phenylephrine occurred between 30 (Figure 1) and $60 \mathrm{~min}$ (Figure 2) after insulin administration. On the other hand, the decrease in hepatic responsiveness to isoproterenol occurred earlier, i.e., between 15 (data not shown) and $30 \mathrm{~min}$ (Figure 1) after insulin injection. Furthermore, during the infusion of adrenergic agonists, the IN group presented lower glycogen breakdown in response to isoproterenol (Figure 1A,B) than during the infusion of phenylephrine (Figure $1 C, D)$, suggesting desensitization of $B$-adrenergic receptors during hypoglycemia. This finding is particularly relevant due to the fact that hepatic $\beta$-adrenoreceptors play an important role in the effect of epinephrine in a large number of experimental conditions (69).

In spite of the findings discussed above, the kinetics of activation of glycogen breakdown promoted by both adrenergic agonists was similar, with peak values obtained $2 \mathrm{~min}$ after initiating the infusion of both adrenergic agonists (Figures 1-4). Stümpel et al. (21) reported similar observations, i.e., decreased hepatic glucose production within 1-2 min of continuous exposure to norepi-
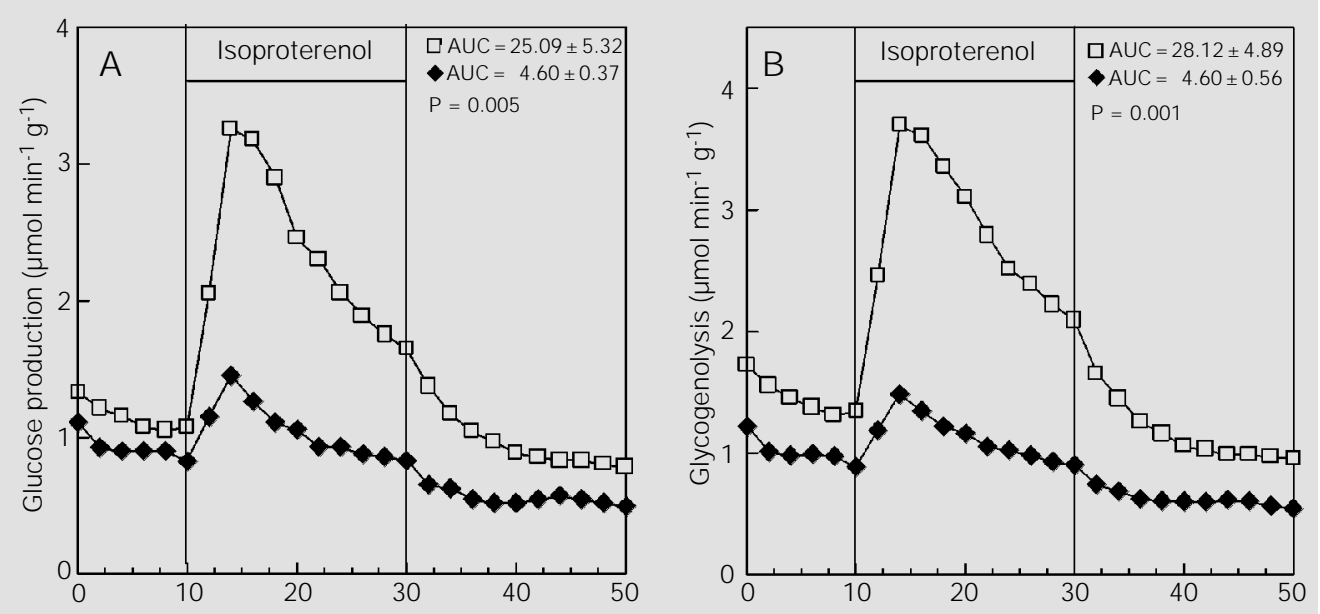

Figure 2 - Effect of isoproterenol $(20 \mu \mathrm{M}$; panels $\mathrm{A}$ and $\mathrm{B})$ and phenylephrine $(2 \mu \mathrm{M}$; panels $\mathrm{C}$ and $\mathrm{D}$ ) on glucose production and glycogenolysis. The data reported are the mean of at least 5 individual liver perfusion experiments performed $60 \mathrm{~min}$ after injection of saline ( $\mathrm{CN}$ group, squares) or insulin (IN group, diamonds). The livers were perfused as described in Material and Methods. AUC = Area under the curve. The statistical test used was the unpaired Student t-test.
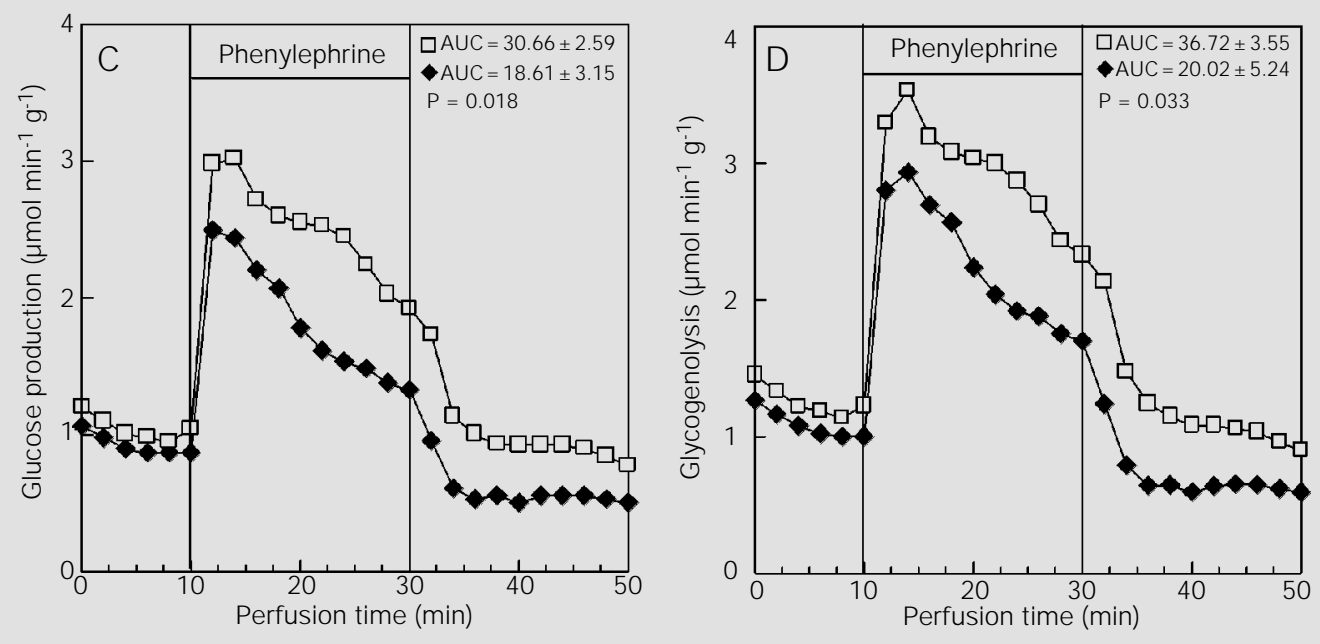
Figure 3 - Effect of isoproterenol $(20 \mu \mathrm{M}$; panels $\mathrm{A}$ and $\mathrm{B})$ and phenylephrine $(2 \mu \mathrm{M}$; panels $\mathrm{C}$ and $\mathrm{D}$ ) on glucose production and glycogenolysis. The data reported are the mean of 5 individual liver perfusion experiments performed 120 min after injection of saline (CN group, squares) or insulin (IN group, diamonds). The livers were perfused as described in Material and Methods. The IN group represents recovered animals, i.e., rats that showed normoglycemia after 120 min of insulin administration. AUC = Area under the curve. The statistical test used was the unpaired Student t-test.
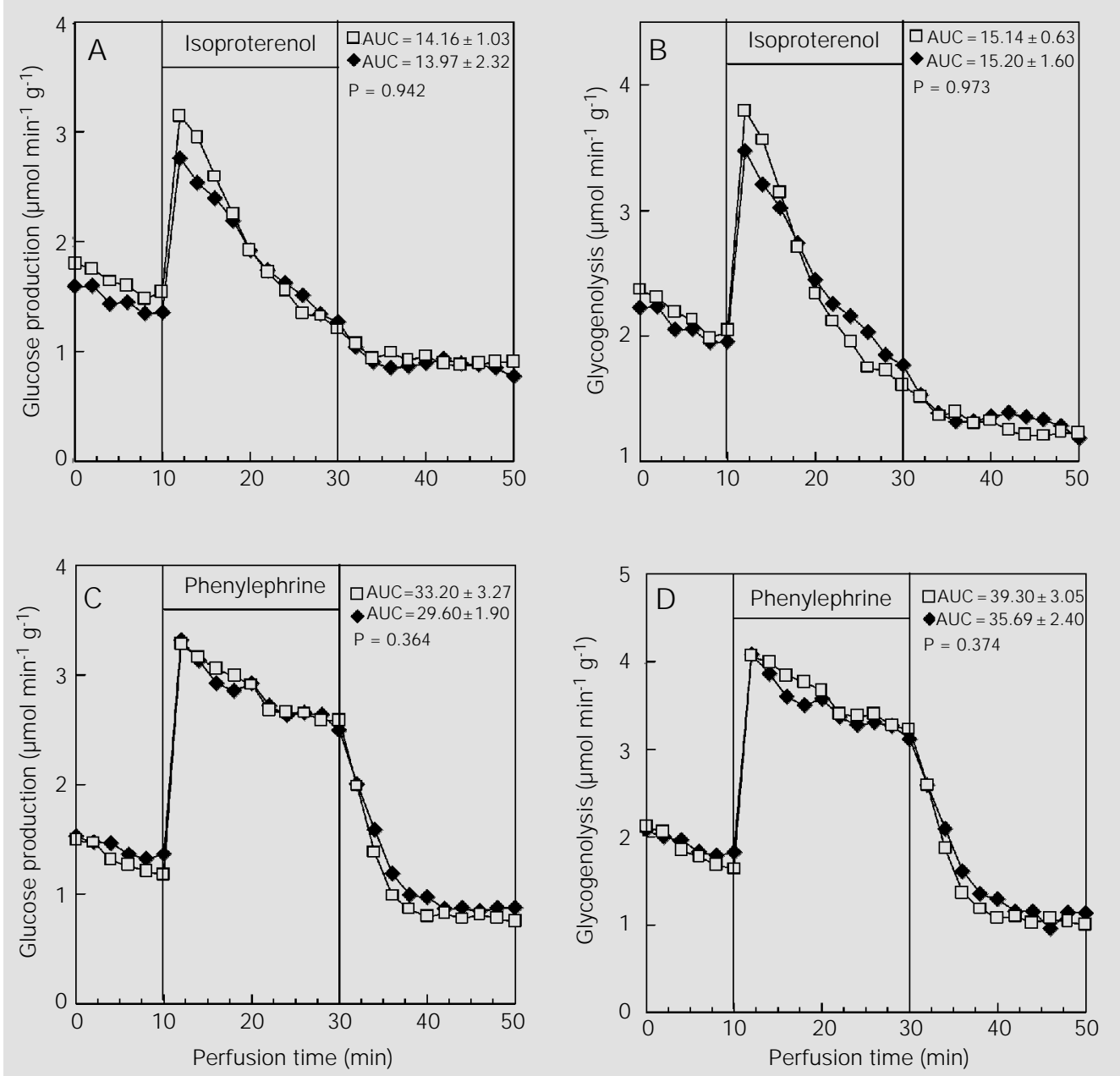

nephrine.

Since the most pronounced changes in the hepatic responsiveness to adrenergic agonists occurred $60 \mathrm{~min}$ after insulin administration (Figure 2), we decided to obtain more information about the factors that control adrenergic responsiveness by carrying out the experiments at this time. For this purpose, two additional sets of experiments were performed.

First, we determined the activity of total glycogen synthase and the proportion of the active form of this enzyme. None of these parameters was affected by IIH (Table 3 ). As previously shown (12), glycogen phosphorylase activity was also not influenced by hypoglycemia. Taken together, these results led us to suggest that hyperinsulinemia promoted by insulin administration $(436.0 \pm 13.2 \mu \mathrm{U} / 1$ of the IN group $v s 47.6 \pm$ $3.8 \mu \mathrm{U} / 1$ of the $\mathrm{CN}$ group - results obtained 60 min after insulin injection) may prevent the effect of an increased endogenous release of counterregulatory hormones promoted by hypoglycemia (22).

Cyclic AMP is known to be the second messenger of $\beta$-adrenergic receptors (23). Thus, due to the fact that the most pronounced changes in glycogen breakdown were observed for isoproterenol, in the second set of experiments the effect of dibutyryl cyclic AMP was tested. As shown in Figure 5 , the kinetics of the activation of glycogen breakdown promoted by dibutyryl cyclic 

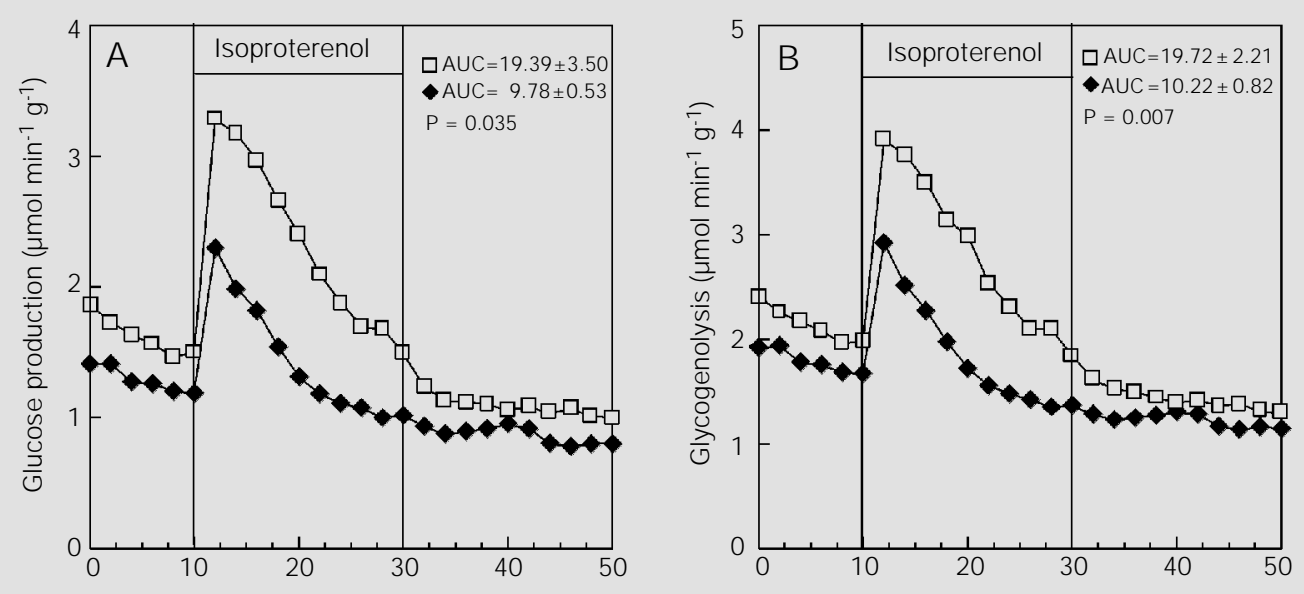

Figure 4 - Effect of isoproterenol (20 $\mu \mathrm{M}$; panels $\mathrm{A}$ and $\mathrm{B}$ ) and phenylephrine $(2 \mu \mathrm{M}$; panels $\mathrm{C}$ and $\mathrm{D}$ ) on glucose production and glycogenolysis. The data reported are the mean of 4 individual liver perfusion experiments performed $120 \mathrm{~min}$ after injection of saline (CN group, squares) or insulin (IN group, diamonds). The livers were perfused as described in Material and Methods. The IN group represents non-recovered animals, i.e., rats that showed hypoglycemia 120 min after insulin administration. AUC $=$ Area under the curve. The statistical test used was the unpaired Student t-test.
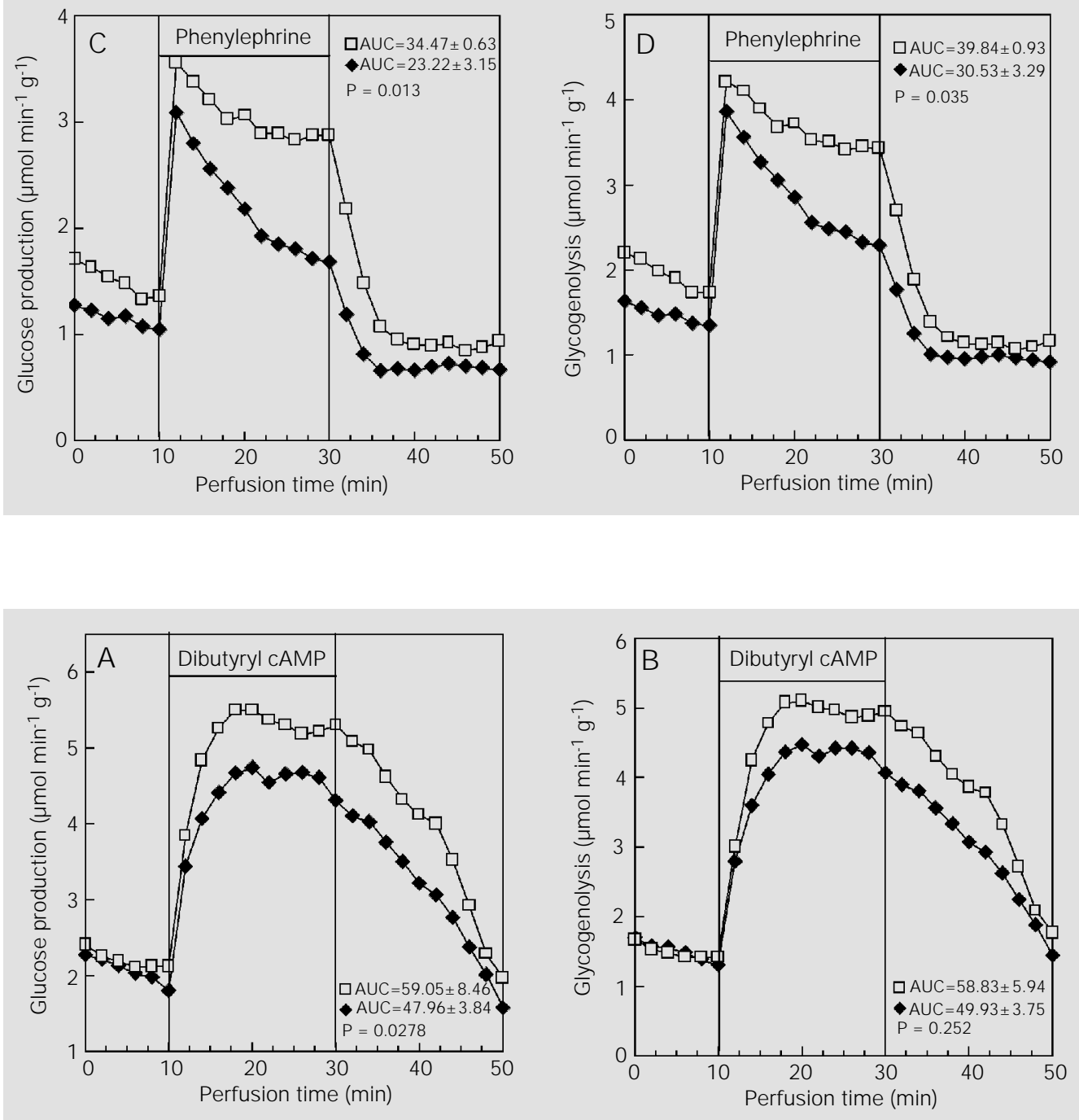

Figure 5 - Effect of dibutyryl cyclic AMP (cAMP; $30 \mu \mathrm{M})$ on glucose production (panel A) and glycogenolysis (panel B). The data reported are the mean of 4 individual liver perfusion experiments performed $60 \mathrm{~min}$ after injection of saline (CN group, squares) or insulin (IN group, diamonds). The livers were perfused as described in Material and Methods. AUC = Area under the curve. The statistical test used was the unpaired Student t-test. 
Table 3 - Activities of the total and active forms of glycogen synthase and proportion of the active form (\%AS) in rats which received saline (CN group, glycemia: $144.7 \pm 2.4 \mathrm{mg} / \mathrm{dl}$ ) or insulin (IN group, glycemia: $42.4 \pm 3.6 \mathrm{mg} / \mathrm{dl}$ ) $1 \mathrm{~h}$ before hepatic perfusion.

Glycogen synthase activity was assayed in liver samples collected $10 \mathrm{~min}$ before the infusion of phenylephrine or isoproterenol (time 0). Data are reported as the mean \pm SEM for 6 rats of glycogen synthase activity $\left(\mathrm{nmol} \mathrm{mg}{ }^{-1} \mathrm{~min}^{-1}\right)$.

\begin{tabular}{lrr}
\hline $\begin{array}{l}\text { Glycogen } \\
\text { synthase } \\
\text { activity }\end{array}$ & \multicolumn{1}{c}{$\mathrm{CN}$} \\
\hline Total & $16.2 \pm 0.55$ & $14.6 \pm 0.55$ \\
Active & $0.7 \pm 0.15$ & $0.65 \pm 0.15$ \\
$\%$ AS & $4.52 \pm 1.16$ & $4.10 \pm 0.57$
\end{tabular}

AMP was similar in both groups. Thus, we conclude that the mechanism of decreased responsiveness to isoproterenol occurred at some step preceding cyclic AMP formation. This effect can occur on receptor, G-protein or adenylate cyclase activity. Current ideas indicate that the initial event in $\beta$-adrenergic desensitization is a rapid uncoupling of the receptor from $\mathrm{G}_{\mathrm{s}}$-protein due to receptor phosphorylation (24). However, if this mechanism operates during IIH remains to be elucidated.

\section{Acknowledgments}

The authors are grateful to Mr. Carlos Eduardo de Oliveira for skillful technical assistance.

\section{References}

1. García-Sáinz J A, Romero-Avila MT, Hernandés RA, Macías-Silva $M$, OlivaresReyes A \& Gonzáles-Espinosa A (1992). Species heterogeneity of hepatic adrenoceptors: $\alpha_{1 A^{-}}, \alpha_{1 B^{-}}$and $\alpha_{1 C}$-subtypes. Biochemical and Biophysical Research Communications, 186: 760-767.

2. El-Refai MF \& Chan TM (1982). Effects of fasting on hepatic catecholamine receptors. FEBS Letters, 146: 397-402.

3. Bazotte RB, Constantin J, Curi R, Kemmelmeier FS, Hell NS \& Bracht A (1989). The sensitivity of glycogenolysis to glucagon, epinephrine and cyanide in livers from rats in different metabolic conditions. Research Communications in Chemical Pathology and Pharmacology, 64: 193-205.

4. Davies AO \& Lefkowitz RJ (1984). Regulation of $ß$-adrenergic receptors by steroid hormones. Annual Review of Physiology, 46: 119-130.

5. Studer RK \& Borle AB (1982). Differences between male and female rats in the regulation of hepatic glycogenolysis. J ournal of Biological Chemistry, 257: 7987-7993.

6. García-Sáinz J A, Huerta-Bahena ME \& Malbon CC (1989). Hepatocyte ß-adrenergic responsiveness and guanine nucleotide-binding regulatory proteins. American J ournal of Physiology, 256: C384C389.
7. Hernández-Sotomayor SMT, Macías-Silva M, Plebanski M \& García-Sáinz J Á (1988). Homologous and heterologous ß-adrenergic desensitization in hepatocytes. Additivity and effect of pertussis toxin. Biochimica et Biophysica Acta, 972: 311-319.

8. Katz MS, McNair CL, Hymer TK \& Boland SR (1987). Emergence of beta-adrenergic-responsive hepatic glycogenolysis in male rats during post-maturational aging. Biochemical and Biophysical Research Communications, 147: 724-730.

9. Itoh H, Okajima F \& Ui M (1984). Conversion of adrenergic mechanism from an $\alpha$ to a ß-type during primary culture of rat hepatocytes. J ournal of Biological Chemistry, 259: 15464-15473.

10. Souza HM, Hell NS, Lopes G, Batista MR \& Bazotte RB (1994). Effect of combined administration of counterregulatory hormones during insulin-induced hypoglycemia in rats: lipolysis mediated by ß-adrenergic mechanism contributes to hyperglycemia. Brazilian J ournal of Medical and Biological Research, 27: 2883-2887.

11. Souza HM, Hell NS, Lopes G, Batista MR \& Bazotte RB (1996). Synergistic effect of combined administration of counterregulatory hormones during insulin-induced hypoglycemia (IIH) in rats: The participation of lipolysis and gluconeogenesis to the hyperglycemia. Acta Pharmacologica
Sinica, 17: 455-459.

12. Lopes G, Lima FB, Hell NS, Vardanega M $\&$ Bazotte RB (1998). The responsiveness of glycogen catabolism to adrenergic agonists during insulin-induced hypoglycemia (IIH) in rat livers. General Pharmacology, 30: 593-599.

13. Bergmeyer HU \& Bernt E (1974). Determination of glucose with glucose-oxidase and peroxidase. In: Bergmeyer HU (Editor), Methods of Enzymatic Analysis. Vol. 2. Academic Press, New York, 1205-1215.

14. Desbuquois B \& Aurbach GD (1971). Use of polyethyleneglycol to separate free and antibody-bound peptide hormones in radioimmunoassays. J ournal of Clinical Endocrinology, 33: 732-738.

15. Ferraz $M$, Brunaldi $K$, Oliveira $C E \&$ Bazotte RB (1997). Hepatic glucose production from L-alanine is absent in perfused liver of diabetic rats. Research Communications in Molecular Pathology and Pharmacology, 95: 147-155.

16. Gutmann I \& Wahlefeld W (1974). L-(+)Lactate. Determination with lactate dehydrogenase and NAD. In: Bergmeyer HU (Editor), Methods of Enzymatic Analysis. Vol. 2. Academic Press, New York, 1464 1472.

17. Czok R \& Lamprecht W (1974). Pyruvate, phosphoenolpyruvate and D-glycerate-2phosphate. In: Bergmeyer HU (Editor), 
Methods of Enzymatic Analysis. Vol. 2. Academic Press, New York, 1446-1448.

18. Kimmig R, Mauch TJ , Kerzl W, Schwabe $U \&$ Scholz R (1983). Actions of glucagon on flux rates in perfused rat liver. 1. Kinetics of the inhibitory effect on glycolysis and the stimulatory effect on glycogenolysis. European Joumal of Biochemistry, 136: 609-616.

19. Hassid WZ \& Abraham S (1957). Chemical procedures for analysis of polysaccharides. In: Colowick SP \& Kaplam NO (Editors), Enzymology. Vol. 3. Academic Press, New York, 34-51.
20. Thomas JÁ, Schlender KK \& Larner J (1968). A rapid filter paper assay for UDPglucose-glycogen glucosyltransferase, including an improved biosynthesis of UDP-14C-glucose. Analytical Biochemistry, 25: 486-499.

21. Stümpel F, Kucera T, Bazotte RB \& Püschel GP (1996). Loss of regulation by sympathetic hepatic nerves of liver metabolism and hemodynamics in chronically streptozotocin diabetic rats. Diabetologia, 39: 161-165.

22. Cryer P (1993). Glucose counterregulation: prevention and correction of hypogly- cemia in humans. American J ournal of Physiology, 264: E149-E155.

23. Garcia C, Pithon-Curi TC, De LourdesFirmano M, Pires-de-M elo M, Newsholme P \& Curi R (1999). Effects of adrenaline on glucose and glutamine metabolism and superoxide production by rat neutrophils. Clinical Science, 96: 549-555.

24. Lefkowitz RJ , Hausdorff WP \& Caron MG (1990). Role of phosphorylation in desensitization of the $ß$-adrenoceptors. Trends in Pharmacological Sciences, 11: 190-194. 